\title{
APPENDIX A: CASE STUDY: MM
}

MM is a 51-year-old male patient who came to see me for the first time to evaluate why he was feeling fatigued, had a dry mouth, and was always thirsty and urinating to excess. He had a history of diabetes but never took medication. His glucose registered as "HI" with $2+$ glucose and $1+$ ketones in the urine but as he had no other complaints and his physical exam was normal; he was sent home after blood was collected for laboratory analysis. This patient refused being sent to the emergency room for these symptoms.

He returned the next day to be reevaluated and discuss the laboratory tests. His pertinent results were as follows:

Glucose: $654 \mathrm{mg} / \mathrm{dL}$

Sodium: $126 \mathrm{mg} / \mathrm{dL}$

Chloride: $86 \mathrm{mg} / \mathrm{dL}$

Total cholesterol: $265 \mathrm{mg} / \mathrm{dL}$

Triglycerides: $1015 \mathrm{mg} / \mathrm{dL}$

HDL: $23 \mathrm{mg} / \mathrm{dL}$

LDL: not calculable

Hemoglobin A1c: 15.1\%

Urine with specific gravity $>1.030$, glucose $3+$, ketone $1+$

That day we instituted an intensive in-office approach. His glucose on arrival was $596 \mathrm{mg} / \mathrm{dL}$ with other vital signs normal. His physical exam remained normal as well with the 
only complaints offered being fatigue and thirst. I started an intravenous (IV) line and gave him 2 liters of normal saline solution. While he was on the IV drip, he was provided a diala-dietician number and spoke with them to get information about how to control his new diagnosis. He received in-person education by myself and my nurse about the medication I would be prescribing him and how to check his glucose and blood pressure. He purchased these RPM products from an online retailer with instructions on how the application they were associated with works, and he was given my email address.

He received 6 units subcutaneous insulin for the hyperglycemia. Glucose and urine were repeated after the first bag of IV fluid and the second. Upon leaving the office he felt better-more hydrated and less fatigued. We repeated the labs, specifically the lipid panel and the chemistry panel, to find:

Glucose: $348 \mathrm{mg} / \mathrm{dL}$

Sodium: $132 \mathrm{mg} / \mathrm{dL}$

Chloride: $93 \mathrm{mg} / \mathrm{dL}$

Total Cholesterol: $267 \mathrm{mg} / \mathrm{dL}$

Triglycerides: $689 \mathrm{mg} / \mathrm{dL}$

This patient was able to be closely monitored using telemedical follow-ups. The next day his glucose at home was 250 $\mathrm{mg} / \mathrm{dL}$ and he no longer complained of thirst and fatigue. He will be closely monitored going forward and utilization of digital health will continue to be implemented.

This case demonstrates how telemedicine, telehealth, and remote patient monitoring can be utilized to keep a patient who otherwise probably would be sent to the emergency room at home. We are lucky that the practice I work for has the IV fluids available, which were vital for this patient's care. The utilization of these services allowed for close monitoring of 
the patient, and he expressed extreme satisfaction in the ability to maintain his care from home and avoid the emergency room, especially since this occurred during the COVID-19 pandemic.

The patient MM gave expressed verbal permission to be included in this text as a case study provided no identifying metrics were given, complying with HIPAA standards. 